\title{
EXTENSÃO DO DOMÍNIO DO MAL: HEIDEGGER E A METAFÍSICA. ELEMENTOS DE UMA ANÁLISE A PARTIR DE LEVINAS
}

\author{
Paulo Cesar Duque-Estrada \\ Pontificia Universidade Católica do Rio de Janeiro
}

RESUMO: O presente artigo procura situar o que constituiria uma resistência ao pensamento de Heidegger já nos textos iniciais de Levinas dedicados ao filósofo alemão. Heidegger estaria estruturalmente vinculado à própria tradição da metafísica que ele procurou ultrapassar. Insistência na questão do ser e fechamento à alteridade constituem, para Levinas, os dois polos inseparáveis de um indelével mal metafísico.

Palavras-chave: Ser, Alteridade, Metafísica, Ontologia, Ética.

ABSTRACT: The present article tries to situate what would constitute a resistance to the thought of Heidegger that is already present in the early texts of Levinas dedicated to the German philosopher. Heidegger would be structurally linked to the very tradition of metaphysics that he sought to overcome. Insistence in the question of being and closure to otherness constitute for Levinas the two inseparable poles of an indelible metaphysical evil.

Keywords: Being, Alterity, Metaphysics, Ontology, Ethics.

\footnotetext{
* O presente texto retoma e desenvolve uma primeira versão publicada com o título "A questão da
} alteridade na recepção levinasiana de Heidegger”; In: Veritas. Porto Alegre. V.51. N. 2. 2006. 
Gostaria de adiantar, logo de início, uma observação: o caráter explicativo, quase pedagógico, dos textos do jovem Levinas sobre Heidegger poderiam nos levar a concluir que, no início de sua trajetória, Levinas se apresentaria como um estudioso do filósofo alemão apenas comprometido com a divulgação e a pesquisa de sua obra em língua francesa, e que somente após a catástrofe da segunda grande guerra ele teria se distanciado teoricamente do autor de Ser e tempo. Na verdade, tratar-se-ia aí de um equívoco. Pois mesmo nos seus textos iniciais, de caráter explicativo, já se pode encontrar indicações precisas de um distanciamento teórico.

Pode-se dizer, de imediato, que se há propriamente, em Levinas, uma crítica à metafísica, ela não se desdobra, como em Heidegger, a partir da questão do ser e de seu esquecimento. Para Heidegger, como se sabe, a problemática central da metafísica consiste em ter pensado o ser como se tratasse de "algo", de um ente. A coisificação ou entificação do ser se confundiria, assim, com a própria história de seu esquecimento. Mas em Levinas, ao contrário, o problema está na própria centralidade ou no primado do ser como horizonte a partir do qual se desdobra a tradição da metafísica. Assim, o que em Heidegger deve ser retomado, a "coisa mesma" prometida e esquecida - por uma espécie de traição congênita, estrutural pela metafísica, é o que, para Levinas, se deve romper. Afinal, é justamente a ligação originária entre pensamento e ser a que Heidegger se refere que leva a metafísica a comportar em si a possibilidade, no dizer de Levinas, de "um consentimento com o horrível".

Como um consentimento com o horrivel é o título de um artigo que Levinas escreveu para o Le Nouvel Observateur (1988), por ocasião do ressurgimento, a partir do livro de Vitor Farias, das discussões sobre o envolvimento de Heidegger com o nazismo. ${ }^{1}$ Levinas discute neste texto não apenas a adesão de Heidegger ao Nazismo, mas, o que lhe parece ainda mais grave e imperdoável, a sua decisão de se manter em silêncio sobre o que ocorreu.

\footnotetext{
${ }^{1}$ Devo a Ricardo Timm de Souza o acesso ao referido artigo de Levinas.
} 
Mas tal consentimento com o horrível não teria nenhuma relevância filosófica se se tratasse apenas de uma condenação pontual referente ao indivíduo Martin Heidegger. Em verdade, a análise de Levinas vai muito mais longe - "nós nos encontramos, no que concerne às relações entre Heidegger e o nacional-socialismo, muito além de simples simpatia ou de antipatia" -, uma vez que ela nos permite pensar o "caso" Heidegger não apenas à luz da estrutura interna de seu pensamento, mas, de uma forma muito mais ampla, como um episódio na grande história de consentimentos com o horrível que perpassam a tradição da metafísica:

O diabólico não se contenta com a condição de maligno que a sabedoria popular lhe empresta e cujas malícias e astúcias encontram-se desgastadas e previsíveis em uma cultura adulta. O diabólico é inteligente. Ele se infiltra onde quer. Para recusálo, deve-se primeiro refutá-lo. É preciso um esforço intelectual para reconhecê-lo. (...) o diabólico dá a pensar. ${ }^{2}$

Antes de mais nada, Levinas reconhece em Heidegger uma crítica importante ao racionalismo ocidental. Qual seria a positividade que Levinas percebe na crítica heideggeriana? A crítica de Heidegger à metafísica desemboca em uma crítica ao moderno paradigma filosófico em que a totalidade do real é reduzida à consciência. Aqui o sujeito se afirma como o lugar ou instância a partir da qual o real é explicado ou explicável. A consciência certa de si mesma se reconhece, pois, em sua presença a si, como fundamento. Ora, esta consciência, na perspectiva levinasiana, é estruturalmente autista; não aberta para a alteridade, para tudo o que em última instância não seja ela mesma. Como em todo reducionismo, também a redução à ordem da consciência significa uma redução da diversidade do real à ordem do Mesmo. Este último, por sua vez - a consciência como

\footnotetext{
${ }^{2}$ LEVINAS, E. Comme un consentement à l'horrible. Le Nouvel Observateur, 22-28, Janvier 1988; minha tradução.
} 
fundamento - se constitui, necessariamente, por uma razão universal e, portanto, impessoal, abstrata, neutra e indiferente em relação ao efetivamente dado. Em Heidegger, de acordo com Levinas, haveria o início de uma crítica a tal reducionismo.

Mas a positividade da crítica heideggeriana a que Levinas se refere, não valeria apenas para as modernas filosofias da consciência, como se estas fossem uma perversão, um desvio, em relação à tradição filosófica anterior. Em verdade, a tradição da filosofia sempre buscou uma chave explicativa da realidade. Ela sempre foi marcada, portanto, por um ideal de redução do real a alguma chave ou fundamento explicativo. É assim que pelo menos de três maneiras importantes Heidegger representaria, segundo Levinas, um início importante e necessário de uma crítica a tal reducionismo:

Em primeiro lugar, a noção de diferença ontológica entre ser e ente representaria um profundo abalo em todo idealismo filosófico, ou seja, em toda e qualquer pretensão de redução do real a um fundamento, à ordem de um Mesmo. Com a diferença ontológica, o fundamento passa a se mostrar como essencialmente desprovido de sua suposta estabilidade auto-idêntica (enquanto ideia, história, matéria, etc.), e intrinsecamente inscrito na instabilidade, que lhe é constitutiva, de uma diferença em relação ao seu próprio modo de ser (a idealidade não é a ideia, a historicidade não é a história, a materialidade não é a matéria, ...).

Em segundo lugar, a diferença ontológica desdobraria uma concepção positiva do próprio ser humano. Este último - ao contrário da tradição do pensamento filosófico - já não se encontraria mais reduzido a um fundamento ou essência que o determinasse enquanto tal. O Dasein (ser-aí) é mera abertura ao ser; em outros termos, é compreensão do ser. Aqui não se daria uma redução a um princípio ou fundamento: compreensão do ser não é um princípio, mas um modo de ser do Dasein, um modo de já estar aí, em meio às coisas e se relacionando com elas. Esse ou aquele modo de já estar aí em relação às coisas ao redor é a compreensão do ser (das coisas e de si próprio). Trata-se, numa palavra, de um modo de ser-nomundo, e não de um princípio que determinaria a essência imutável do ser 
humano. Como diz Levinas, "certamente, se considerarmos o homem como um ente, a compreensão do ser constitui a essência deste ente." ${ }^{3}$ Isto poderia, a princípio, sugerir uma redução do ser humano a uma essência; esta última seria a própria compreensão do ser. No entanto, continua Levinas: "Mas precisamente, e aí está uma característica fundamental da filosofia heideggeriana, a essência do homem é ao mesmo tempo a sua existência." 4 Ora, como se sabe, "existência", em Heidegger, quer dizer "ser-no-mundo" que, sempre, se dá ou acontece à luz de uma compreensão do ser. Diz Levinas: "Aquilo que o homem é, é ao mesmo tempo o seu modo de ser, a sua maneira de existir, de se temporalizar." ${ }^{5}$ Em resumo, ser, para o ser-aí, é compreender o ser. Portanto, se o ser humano é compreensão do ser, e compreensão do ser é um modo de existir ou de ser-no-mundo; logo, não há uma essência que pré-determine o ser humano; a sua essência está em existir, de um ou de outro modo, enquanto ser-no-mundo:

Em resumo, o problema do ser que Heidegger coloca reconduz-
nos ao homem, pois o homem é um ente que compreende o ser.
Mas, por outro lado, essa compreensão do ser é ela própria o
ser; ela não é um atributo, mas o modo de existência do
homem.

Em terceiro lugar, com a sua "questão do ser", Heidegger traz para o pensamento uma importante radicalização da experiência da alteridade. Na medida em que o ser não é ente algum - embora todo ente precise de um "outro", ou seja, do seu ser, para ser aquilo que é -, tem-se aqui a problemática de uma alteridade radical, a alteridade do próprio ser, que é de uma importância decisiva para o abalo da soberana auto-identidade do Mesmo inerente à tradição da metafísica ocidental.

${ }^{3}$ LEVINAS, E. Martin Heidegger e a Ontologia. In: Descobrindo a Existência com Husserl e Heidegger. Lisboa: Instituto Piaget, 1997. p. 74.

${ }^{4}$ Ibid.

${ }^{5}$ Ibid., 75.

${ }^{6}$ Ibid., p. 76. 
E, no entanto, segundo Levinas, estas três características positivas não levam Heidegger a romper com esta mesma tradição que ele pretende ultrapassar. A questão do ser não leva, efetivamente, a um rompimento com a soberania metafísica do Mesmo. Voltada para a interrogação sobre o que é o ente, "a filosofia foi, desde sempre, atingida por um horror ao outro, (...) por uma alergia insuperável em relação à alteridade. É por isso que ela é essencialmente uma filosofia do ser, que a compreensão do ser é a sua última palavra e a estrutura fundamental do homem." 7

Mas em que consistiria, já nos seus textos iniciais, ainda de aparência meramente explicativa, a reserva de Levinas em relação a Heidegger? Não há dúvida quanto à gravidade - muito além de um simples desacordo intelectual - que motiva o distanciamento de Levinas para com Heidegger. Em A Ontologia no temporal, publicado em 1940, apesar ${ }^{8}$ de se tratar de um simples comentário explicativo de Ser e tempo, Levinas encerra o texto com as seguintes palavras:

A ontologia de Heidegger dá os acordes mais trágicos e torna-se o testemunho de uma época e de um mundo que talvez amanhã seja possível ultrapassar. ${ }^{9}$

O cerne da discussão proposta por Levinas incide sobre o que fundamentalmente encontra-se em jogo no pensamento de Heidegger: a questão do ser.

Apesar de um certo abalo que provoca sobre a auto identidade do fundamento, a questão do ser, segundo Levinas, acaba por retomar, com ainda

\footnotetext{
${ }^{7}$ LEVINAS, E. O vestígio do Outro. In: Descobrindo a Existência com Husserl e Heidegger. Lisboa: Instituto Piaget, 1997. p. 229.

8 Devo esta constatação a Jacques Taminiaux, em seu artigo "The early Levinas's reply to Heidegger's fundamental ontology"; In: Philodophy \& Social Criticism - vol. 23 n.6. 1977.
}

${ }^{9}$ LEVINAS, E. A Ontologia no Temporal. In: Descobrindo a Existência com Husserl e Heidegger. Lisboa: Instituto Piaget, 1997. p. 111. 
mais força, a própria auto-referencialidade inerente ao desdobramento da metafísica. É, aliás, neste sentido que, ao contrário de Heidegger - para quem é somente com Descartes que o ente (i.e., o que quer que seja de algum modo) passa a ser definido "pela primeira vez" a partir do "Eu", ou seja, "como a objetividade do representar" toda filosofia é, para Levinas, uma "egologia":

É a lição de Sócrates, que apenas deixa ao mestre o exercício da maiêutica: todo o ensinamento introduzido na alma já aí se encontrava. A identificação do EU [instância redutora por excelência] - a maravilhosa autarquia do eu - é a prova natural dessa transmutação do Outro em Mesmo. ${ }^{11}$

Mas voltemos ao caráter auto referencial do pensamento de Heidegger. Se o ser nada é, se o ser não é ente algum, se há um nada do ser; correlativamente, como o ser-aí que somos nós se caracteriza, fundamentalmente, enquanto compreensão do ser - ou, o que vem a dar no mesmo, por uma "abertura ao ser" -, e nada mais; então, também o ser-aí é um nada. Ainda nos termos de Heidegger, o ser-aí é uma potencialidade-de-ser que aponta para uma possibilidade última (ser-para-a-morte) de não poder mais ser possível seguir sendo potencialidade-de-ser. O ser-aí é tão somente isso, fundamentalmente, e nada mais. Há, portanto, correlativamente, o nada do ser e o nada do ser-aí. Assim, se, por um lado, esse nada heideggeriano abala toda e qualquer pretensão de redução ao fundamento, por outro lado, com esse nada, Heidegger não faz mais do que recolocar - prolongando o autismo metafísico que é alvo de sua critica - a sua própria filosofia do nada como centro, referência única, para se pensar a verdade (o ser) de tudo. Ele não precisa lançar mão de nenhum fundamento, de coisa nenhuma, de ente algum, para afirmar o seu pensamento no cerne da verdade de tudo:

\footnotetext{
${ }^{10}$ Permito-me aqui referir ao meu artigo "Ciência e pós-representação: notas sobre Heidegger", In: Politica \& Trabalho. Revista de Ciências Sociais, n. 24, abril 2006.

${ }^{11}$ LEVINAS, E. A Filosofia e a Ideia de Infinito. In: Descobrindo a Existência com Husserl e Heidegger. Lisboa: Instituto Piaget, 1997. p. 204; meu acréscimo de colchete.
} 
A filosofia de Heidegger descobre o nada em que ela se assenta. O que significa também que ela não assenta em nada que não seja ela própria. (...) a filosofia de Heidegger constitui, portanto, a mais própria realização da existência humana enquanto ser-aí no mundo. ${ }^{12}$

Há uma sobreposição entre o nada do ser e o nada do ser-aí. Ora, fundamentalmente, trata-se de uma única e mesma coisa: o ser-aí é o próprio ser; a relação a si do ser-aí - e essa é a própria ideia de Autenticidade em Heidegger - é relação ao ser. É neste sentido que o pensamento de Heidegger só se refere a ele mesmo; pensar é pensar o ser - e também, ao mesmo tempo, a autêntica relação a si - e nada mais.

É preciso, então, romper com o paradigma do ser, uma vez que não há na metafísica, incluindo Heidegger, uma verdadeira experiência do outro para além de todo e qualquer princípio explicativo ou interpretativo. É preciso, pois, romper com a ontologia, em direção a uma ética em que a experiência primeira, ao contrário do que pretende Heidegger, não é experiência do ser, mas do outro.

Esta postura de pensamento - que se decide por um rompimento com o paradigma da relação ao ser, em nome da relação com o "outro" - não é apenas representativa de uma discussão pontual com Heidegger; ela constitui um traço configurador do pensamento levinasiano, enquanto pensamento marcado por um movimento em direção ao outro. É assim que a própria ideia de verdade se liberta de uma adesão massiva à ordem do Mesmo que, em Heidegger, se potencializa na onipresença de uma relação a si espectral; ou seja, relação do nada do ser-aí com o nada do ser, ou ainda, o que vem a dar no mesmo, relação do nada do ser consigo mesmo. A verdade se afirma aqui, fundamentalmente, na insistência da relação do ser consigo mesmo. Em Levinas, ao contrário, a verdade implica um movimento em direção à transcendência, ao que está para além:

\footnotetext{
${ }^{12}$ Ibid., meu itálico.
} 
Toda a filosofia procura a verdade. Também as ciências podem definir-se por esta procura, pois herdam do eros filosófico, nelas vivente ou adormecido, a sua nobre paixão. Mas, se a definição parece demasiado geral, algo vazia, ela permite distinguir duas vias em que o espírito filosófico se compromete e que esclarecem a sua fisionomia. Essas vias cruzam-se na própria ideia de verdade. Primeiro, verdade implica experiência.

O pensador mantém na verdade uma relação com uma realidade distinta dele, uma realidade outra. Absolutamente outra, segundo a expressão retomada por Jankélévitch. Com efeito, a experiência só merece esse nome se nos transportar para lá daquilo que permanece na nossa Natureza.

A verdadeira experiência deve até conduzir-nos para lá da natureza que nos rodeia, a qual não tem ciúmes dos maravilhosos segredos que guarda, e verga-se, de conivência com os homens, às suas razões e invenções.

Também nela os homens se sentem em casa. A verdade indicaria assim, a chegada de um movimento que parte de um mundo intimo e familiar - mesmo que ainda não o tenhamos explorado inteiramente em direção ao estranho, a um mundo além, como havia dito Platão. A verdade implicaria mais do que uma exterioridade, a transcendência. ${ }^{13}$

Verdade, portanto, comporta um traço de heteronomia (movimento em direção ao "absolutamente outro") irredutível a toda autonomia - heideggeriana ou classicamente metafísica - que consiste na redução do outro ao Mesmo. É neste sentido, continua Levinas, que "a filosofia ocupar-se-ia do absolutamente diferente, seria a própria heteronomia." 14 No entanto, com a sua permanente e insistente auto-referencialidade, a tradição da filosofia, incluindo Heidegger, realizaria - na "maior parte das vezes" - precisamente o oposto. Haveria, pois, uma desproporção entre aquilo que a filosofia se propõe fazer e aquilo que ela de fato faz: "A filosofia [em nome da verdade; do que está para além; portanto, do transcendente ou absolutamente diferente ou outro] empenhar-se-ia em reduzir ao Mesmo tudo aquilo que se opõe a ela como outro. Ela marcharia para uma autonomia, para um estágio onde nada de irredutível viria limitar o pensamento (...)." ${ }^{15}$ Paradoxalmente, a autonomia -

\footnotetext{
${ }^{13}$ Ibid., p. 201; meu itálico.

${ }^{14}$ Ibid., 202.

${ }^{15}$ Ibid., p. 201; meu colchete.
} 
redução do outro ao Mesmo - viria enclausurar e, na clausura, determinar a própria ideia de liberdade.

Tratar-se-ia, pois, de uma relação paradoxal, porém estrutural, entre, de um lado, o "livre pensar", movido pelo ideal de verdade, e, de outro, a redução de tudo ao Mesmo. A íntima vinculação entre liberdade e reducionismo constituiria, pois, a verdade do valor "autonomia". No dizer de Levinas: "A conquista do ser pelo homem através da história - eis a fórmula a que se resume a liberdade, a autonomia, a redução do Outro ao Mesmo. ${ }^{16}$

Eis também uma importante chave de análise, aberta por Levinas - para muito além da pontualidade efêmera da simples acusação, ou de meras simpatias e antipatias -, para se refutar e resistir ao Mal.

${ }^{16}$ Ibid., p. 202. 


\section{REFERÊNCIAS}

DUQUE-ESTRADA, Paulo Cesar. A questão da alteridade na recepção levinasiana de Heidegger. Veritas, Porto Alegre. v. 51, n. 2, p. 29-35, jun. 2006.

Ciência e pós-representação: notas sobre Heidegger. Política \&e Trabalho. Revista de Ciências Sociais, João Pessoa, n. 24, p. 59-71, abril 2006.

LEVINAS, Emmanuel. A Filosofia e a Ideia de Infinito. In: Descobrindo a Existência com Husserl e Heidegger. Lisboa: Instituto Piaget, 1997. p. 201-216.

A Ontologia no Temporal. In: Descobrindo a Existência com Husserl e Heidegger. Lisboa: Instituto Piaget, 1997. p. 97-111.

Comme un consentement à l'horrible. Le Nouvel Observateur, 22-28, p. 48-49, Janvier 1988.

Martin Heidegger e a Ontologia. In: e Heidegger. Lisboa: Instituto Piaget, 1997. p. 69-96.

O vestígio do Outro. In: Descobrindo a Existência com Husserl e Heidegger. Lisboa: Instituto Piaget, 1997. 227-245.

TAMINIAUX, Jacques. The early Levinas's reply to Heidegger's fundamental ontology. Philosophy \& Social Criticism, v. 23, n.6, p. 29-49, 1977. 